\title{
Artigos
}

\section{Os vinte anos da Educação na Interface: trajetória, tendências e desafios}

Twenty years of Education in Interface: trajectory, trends and challenges (abstract: p. 17)

Los veinte años de Educación en Interface: trayectoria, tendencia y desafíos (resumen: p. 18)

\section{Mara Regina Lemes De Sordi(a) \\ <maradesordi14@gmail.com>}

Marcos Henrique Almeida dos Santos ${ }^{(b)}$ $<$ m163183@dac.unicamp.br>

Geisa do Socorro Cavalcanti Vaz Mendes(c)

<geisavaz@gmail.com> iD

\author{
(a) Departamento de Ensino e Práticas \\ Culturais, Faculdade de Educação, \\ Universidade Estadual de Campinas \\ (Unicamp). Avenida Bertrand Russell, \\ 801, Cidade Universitária Zeferino \\ Vaz. Campinas, SP, Brasil. 13083- \\ 865. \\ (b) Pós-graduando do Programa de \\ Pós-Graduação em Educação \\ (Doutorado), Faculdade de Educação, \\ Unicamp. Campinas, SP, Brasil. \\ (c) Programa de Pós-Graduação de \\ Mestrado Profissional em Educação, \\ Faculdade de Educação, Unicamp. \\ Campinas, SP, Brasil.
}

O texto resgata os vinte anos do eixo Educação na revista Interface e problematiza essa trajetória a partir de suas publicações. 0 olhar para esses trabalhos revela as tendências predominantes e reflete acerca dos desafios para as próximas décadas. As categorias de análise: Formação Profissional em Saúde; Políticas de Reorientação da Formação Profissional em Saúde/Docência em Saúde; Práticas Educativas em Saúde e Fundamentos Teóricos e/ou Metodológicos da Educação são acionadas para contemplar o conjunto de temáticas abordadas pelos autores no período histórico do estudo e nos diferentes espaços da revista, em estreita relação com suas finalidades no âmbito da socialização do conhecimento no campo da educação e saúde. Conclui-se que o periódico tem se mostrado espaço importante de sistematização e reflexões tanto dos desafios gerais da educação quanto dos específicos da educação em saúde, potencializando avanços qualitativos na formação profissional.

Palavras-chave: Educação e saúde. Formação profissional. Socialização do conhecimento. Vinte anos de Interface. 


\section{Introdução}

A celebração dos vinte anos da Interface ensejou a oportunidade de refletirmos a respeito de seus caminhos e realizarmos um mapeamento das produçóes do período relacionadas ao eixo Educação. Sem perder conexão com os demais eixos Comunicação e Saúde -, focalizamos a lente para o que se tem escrito na Educação, em que se "prioriza abordagens críticas e inovadoras bem como modos qualitativos de investigação", consoante ao descrito no escopo e política editorial da revista.

A bem da verdade, confessamos, a priori, nossa identificação com o periódico Interface, que tem repercutido em nossas reflexôes teóricas e inspirado esforços de atuação nos contextos práticos referenciados por uma formação humana que não dissocia as múltiplas dimensões do fenômeno educacional. A riqueza dos diálogos com as diferentes formas de produzir conhecimentos em educação e saúde e sua articulação com a Filosofia, as Artes e as Ciências Sociais e Humanas têm se mostrado potente para a ampliação de nossa visão e afetado nosso processo de trabalho docente. Realizar esse mapeamento nos permite conhecer mais de perto as tendências investigativas e as experiências compartilhadas pelos pesquisadores autores, que elegem a Interface como instância de comunicação com seus pares; e contribuir para a visibilidade das temáticas que estudam de modo a, quem sabe, intensificar trocas de saberes plurais e complementares de um modo solidário e ético.

Na primeira seção apresentamos os caminhos trilhados para organização do banco de dados da revista e socializamos o fruto desse processo, a partir da tabulação das informações. Essa tabulação possibilitou identificar as temáticas mais recorrentes e definir categorias de análise, que consideram as pesquisas e experiências socializadas no decorrer de vinte anos por autores pertencentes a diferentes contextos. Destacamos, na segunda seção, a tensão entre os artigos enviados e as temáticas induzidas, além da forma como buscam atender a mudanças, principalmente a partir da reorientação da formação em saúde. Dando continuidade a essa discussão, apresentamos, na terceira seção, uma breve retrospectiva dos ensaios, dossiês e suplementos temáticos pautados no decorrer dos vinte anos, com destaque às publicações relacionadas ao eixo Educação.

Tomando como referência as principais temáticas aludidas nas diferentes categorias, a quarta e última seção do artigo, de caráter conclusivo, sinaliza alguns significados da trajetória da revista, os desafios à produção acadêmica e ao trabalho no campo da educação, em especial educação em saúde, considerando o atual contexto que vivemos. Assim, enfatizamos a centralidade do periódico como espaço de resistência e organização dos atores implicados com novos paradigmas formativos, bem como a discussão de temas emergentes e de cunho contra-hegemônico (questóes de gênero, educação interprofissional, entre outros). Reforçamos a relevância deste artigo dos vinte anos da Interface enquanto memória dessas resistências e lutas, que são levadas adiante no campo das políticas públicas socialmente referenciadas.

\section{Os caminhos trilhados para o desenvolvimento do estudo}

O desafio de realizar o estudo, de cunho predominantemente qualitativo, conforme Minayo $^{1}$, fundamentado na análise de conteúdo proposta por Bardin ${ }^{2}$, resultou na produção deste artigo, que se originou de uma demanda pautada pela equipe editorial da revista. Essa equipe considerou nosso trânsito no campo da educação, em especial 
o debate alusivo da relação entre educação e saúde, com destaque à formação para a docência universitária.

A opção de revisitar os vinte anos de construção deste periódico nos remeteu a determinadas escolhas, expressando apenas uma possibilidade dentre tantas outras. $\mathrm{O}$ compromisso assumido em focar um dos pilares da revista (educação) definiu o ponto de chegada demandado, mas o ponto de partida se mostrou um trabalho complexo.

Nesse sentido, a análise de conteúdo ${ }^{2}$ nos pareceu apropriada para realizar o estudo. Feita essa opção teórica, iniciamos o estudo seguindo as fases propostas por Bardin². Para tanto, recorremos a um banco de dados preexistente, em formato de planilha Excel, previamente constituído, ainda não explorado e disponibilizado pela equipe editorial, com informaçóes relativas aos trabalhos publicados na revista no período de 1997 a 2017, no eixo Educação.

O banco identifica as publicações por ano, volume, número e seção da revista; indica título, palavras-chave, autores e suas respectivas afiliaçôes institucionais; e sinaliza informaçốes complementares, a saber: datas de submissão, aprovação e publicação, e citação do trabalho no Scielo. O banco disponibilizado apresentava uma prévia classificação, sinalizando temáticas ou o formato das publicaçôes (conceitual, empírico, relato) correspondentes ao período de 1997 a 2014.

A partir desse banco, após uma leitura flutuante, enveredamos em busca de complementação das informações, tendo em vista que identificamos que ele ainda estava inconcluso em alguns aspectos. Esse primeiro olhar para os dados denominamos de pré-análise ${ }^{2}$.

A formatação geral do banco foi fundamental para facilitar sua atualização, desde a identificação e organização das informaçôes as quais permitiram a tabulação. Ademais, houve necessidade, em alguns casos, de recorrer aos dados presentes no portal da revista, integrado ao Scielo, para inclusão de alguns elementos. No tocante às publicações referentes ao período de 2015 a 2017, conseguimos identificar, por meio do acesso ao portal, outras publicações do eixo Educação, particularmente quando visualizamos os títulos, palavras-chave e, em algumas delas, os resumos. Isso posto, optamos por incluí-las também no banco. Organizado o banco, utilizamos a ferramenta tabela dinâmica (Excel) para estabelecer cruzamentos de informações, ordenar e classificar o conteúdo das publicaçôes. Esse movimento metodológico corresponde ao que Bardin ${ }^{2}$ denomina de segunda fase "exploração do material” para elaboração de "indicadores” que fundamentem a interpretação dos dados.

Cabe esclarecer que no período de 1997 a 2017, a Interface publicou um total de 1799 documentos, conforme pode ser apreciado na Tabela 1.

Desse total, nosso corpus ${ }^{2}$ de análise foi constituído por 452 publicações, afetas ao eixo Educação e à sua articulação com a Saúde e a Comunicação, conforme o escopo interdisciplinar do periódico, notadamente no que se refere à formação de profissionais de saúde. São publicaçôes que contemplam em seu título palavras-chaves e/ou resumos e descritores específicos do campo da educação, tendo em vista sua compreensão como mediação no seio da prática social global, defendida por Saviani ${ }^{3}$, cuja essência consiste no "[...] ato de produzir, direta e intencionalmente, em cada indivíduo singular, a humanidade que é produzida histórica e coletivamente pelo conjunto dos homens"3 (p. 13). 
(e)

Tabela 1. Publicações da Revista Interface (Comunicação,

Saúde, Educação) no período de 1997 a 2017

\begin{tabular}{cc} 
Tipos de documento & Quantidade \\
\hline Artigo de pesquisa & 1498 \\
Editorial & 61 \\
Indefinido & 60 \\
Resenha de livro & 43 \\
Resumo & 31 \\
Comunicação rápida & 30 \\
Artigo comentado & 24 \\
Relatório breve & 23 \\
Artigo de revisão & 8 \\
Correção & 6 \\
Termo aditivo & 4 \\
Relato de caso & 4 \\
Carta & 4 \\
Notícia & 2 \\
Comunicado de imprensa & 1 \\
Total & 1799 \\
\hline
\end{tabular}

Fonte: Banco de dados Interface (2018).

Essas publicações estão presentes nas diferentes seções da revista, conforme se observa no Gráfico 1.

Gráfico 1. Quantitativo de publicações (Educação) por seção da Revista Interface Período: 1997 a 2017

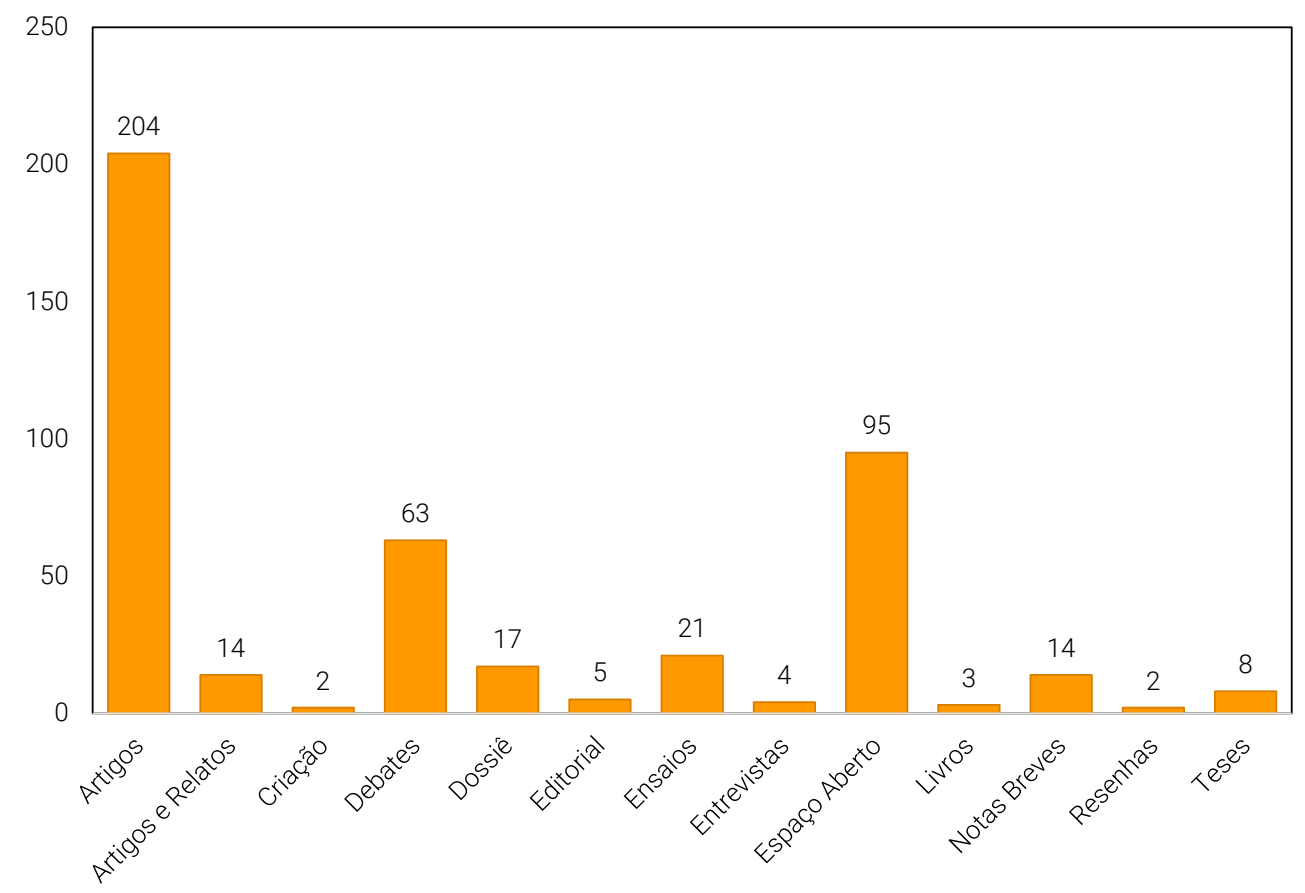

Fonte: Elaborado pelos autores 
Considerando a afiliação institucional dos diferentes profissionais e pesquisadores que publicaram na revista, identificamos 414 publicações nacionais (Brasil), 28 internacionais (Argentina, Canadá, Chile, Colômbia, Espanha, Inglaterra, México, Portugal e Venezuela) e dez publicaçóes conjuntas entre autores atuantes em instituiçôes brasileiras e de outros países (Argentina, Austrália, Canadá, Espanha, Inglaterra, Portugal e Finlândia).

Entre as publicações nacionais, a maior parte é de autores afiliados a instituiçóes da região Sudeste, totalizando 247 trabalhos; seguida da região Sul, que apresentou 75 artigos. A região Nordeste abrange 43 estudos; há 37 publicaçóes inter-regionais; o centro-oeste participou com 11 trabalhos; e, por fim, há apenas um registro de publicação da regiấo norte. A concentração de trabalhos na região Sudeste está relacionada, em alguma medida, ao desenvolvimento da pesquisa no país por meio da criação dos principais programas de pós-graduação stricto sensu localizados nessa região.

Optamos pela análise temática ${ }^{2}$ como modalidade de análise de conteúdo para compreendermos as tendências predominantes nessas publicações. Inicialmente, a partir da leitura do banco de dados, as unidades de registros que consideramos foram o título e as palavras-chave de cada uma das 452 publicaçóes selecionadas. No processo de inferência ${ }^{2}$, terceira fase, constatamos a necessidade de recorrer, em alguns momentos, à leitura do resumo da publicação, uma vez que o título e a palavra-chave se revelaram insuficiente para esse processo. A inferência foi um processo anterior à interpretação, que possibilitou-nos definir as categorias de análise.

Durante a inferência ${ }^{2}$, optamos por classificar as publicações em temáticas e subtemáticas, considerando inclusive algumas das temáticas previamente sinalizadas no banco que nos foi disponibilizado, conforme apontamos anteriormente.

\section{As tendências predominantes nos vinte anos da Revista: a educação em foco}

Apontamos a diversidade e a riqueza de temáticas/subtemáticas dissertadas nas publicações de fluxo contínuo da revista, descritas a seguir.

\section{Educação e trabalho em saúde}

Perfil e identidade profissional; relação usuários-profissionais; relaçóes médicopaciente; educação médica; medicina narrativa; participação; medicalização na educação e saúde; saúde pública; saúde mental e atenção básica; saúde da família; segurança alimentar e nutricional; narrativas; assistência ambulatorial; trabalho vivo; ecologia de saberes; educação pelo trabalho em saúde; educação interprofissional; interprofissionalidade; intersetorialidade; Sistema Único de Saúde; educação continuada; residência multiprofissional em saúde; educação permanente; educação popular; e integração ensino-serviço foram as temáticas/subtemáticas encontradas, totalizando cerca de cem publicaçóes. 
(2)

\section{Pesquisa e prática pedagógica}

Relação professor-aluno; metodologias de ensino-aprendizagem; metodologias de pesquisa; metodologias ativas; problematização e aprendizagem baseada em problemas; metodologias na educação médica; narrativas (pesquisa/formação); e tecnologias e educação totalizaram cerca de oitenta publicações.

\section{Currí́culo e projeto pedagógico}

Inovação curricular; diretrizes curriculares; currículo da educação médica; medicina baseada em evidências; interdisciplinaridade e transdisciplinaridade; concepçôes e paradigmas de formação; saberes; práticas e propostas curriculares; representaçóes alusivas ao currículo; e estágio curricular totalizaram cerca de sessenta publicaçóes.

\section{Formação universitária}

Missão; vocação e função da universidade; autonomia universitária; reforma universitária; trote na universidade; ética; violência; humanização; disseminação do conhecimento; aprendizagem; integração universidade-comunidade; extensão; saúde do estudante; relações interprofissionais; cotidiano universitário; educação a distância e tecnologias na educação superior; e educação especial totalizaram cerca de cinquenta publicações.

\section{Avaliação}

Institucional, externa, da aprendizagem, curricular, do processo formativo, de intervençôes sociais, de políticas e programas, de projeto pedagógico de curso, avaliação acadêmica do livro e qualidade do ensino totalizaram cerca de trinta publicações.

\section{Formação e trabalho docente}

Didática e docência no ensino superior; pesquisa-ação; e políticas de formação do professor universitário totalizaram cerca de vinte publicações.

\section{Teorias e Educação}

Aprendizagem; antropologia e educação; filosofia da educação; formação humana; educação e psicanálise; educação e marxismo; trabalho e educação; pedagogia históricocrítica; teoria da atividade histórico-cultural; cultura moral e educação; etnocentrismo; educação e tecnologia; produção do conhecimento científico (cerca de vinte publicaçóes).

\section{Teorias e Educação em Saúde}

Fundamentos históricos da educação médica; antropologia cultural e etnopsicologia; concepções e paradigmas de formação; pedagogia crítica na educação médica; relações interpessoais; fenomenologia heideggeriana; referencial arendtiano; Medicina antroposófica; Medicina narrativa; Medicina baseada na prova; pedagogia científica; e antropologia médica totalizaram cerca de vinte publicações. 
(2)

Observa-se, no gráfico 2, a tendência em termos percentuais de cada uma dessas temáticas.

Gráfico 2. Temáticas abordadas nas publicações (Educação) de fluxo contínuo

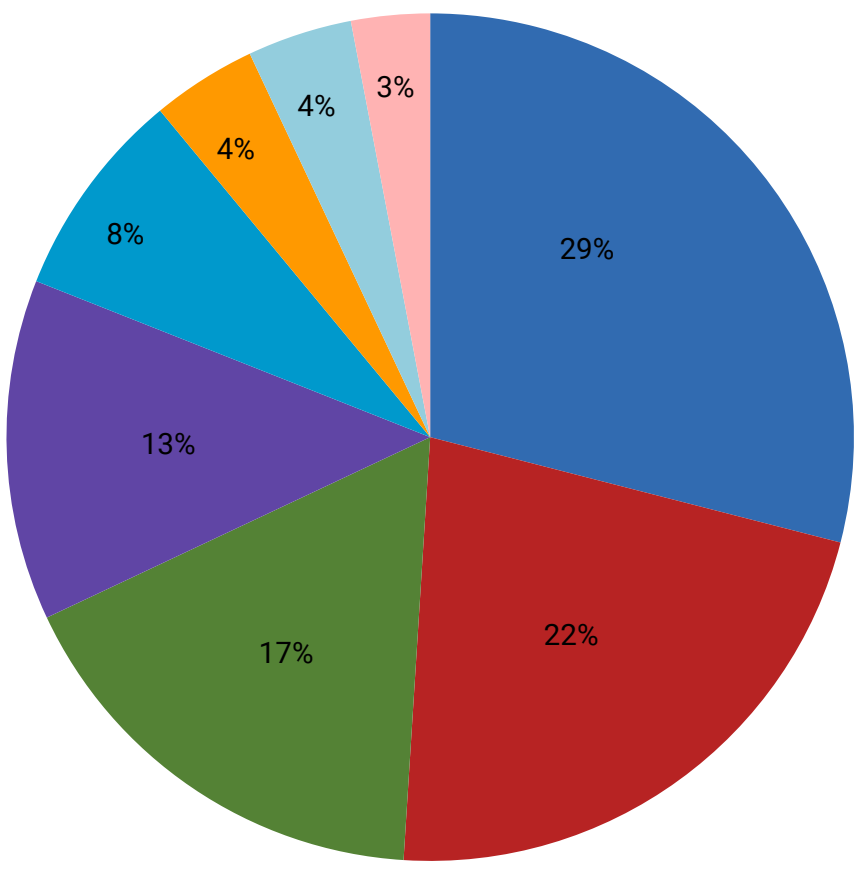

- Educação e trabalho em saúde

- Pesquisa e prática pedagógica

- Currículo e projeto pedagógico

- Formação universitária

- Avaliação

- Formação e trabalho docente

- Teorias e educação

- Teorias e educação em saúde

Fonte: Elaborado pelos autores

A partir do processo de inferência, que ensejou essa classificação temática, compreendemos que a estrutura aberta da revista, com fluxo contínuo, é fortemente demandada pelos pesquisadores da área da saúde e da educação, que acabam imprimindo marcas à revista no que tange aos referenciais teóricometodológicos mais presentes nas produçóes ou relatos de experiência. Importa acentuar que a submissão ativa de textos é também intensamente afetada pela priorização de temas indutores de reflexão que abarcam as formas de produzir saúde e produzir conhecimentos em saúde.

Nesse sentido, tomando-se como referência as temáticas mais recorrentes identificadas no levantamento, elegemos quatro categorias de análise. Não consideramos o rigor de apresentar quantitativamente a relação direta, unidirecional entre temática versus categoria de análise, tendo em vista a amplitude de cada categoria definida e das suas interfaces com as diferentes temáticas/ subtemáticas apontadas. Essas perpassam mais de uma categoria, a partir da diversidade de discussóes, experiências e estudos que configuram a produção e a socialização do conhecimento na área da educação e saúde. O gráfico 3 facilita a visualização sintética das categorias, que são problematizadas em seguida. 
Gráfico 3. Classificação das publicações (Educação) em categorias

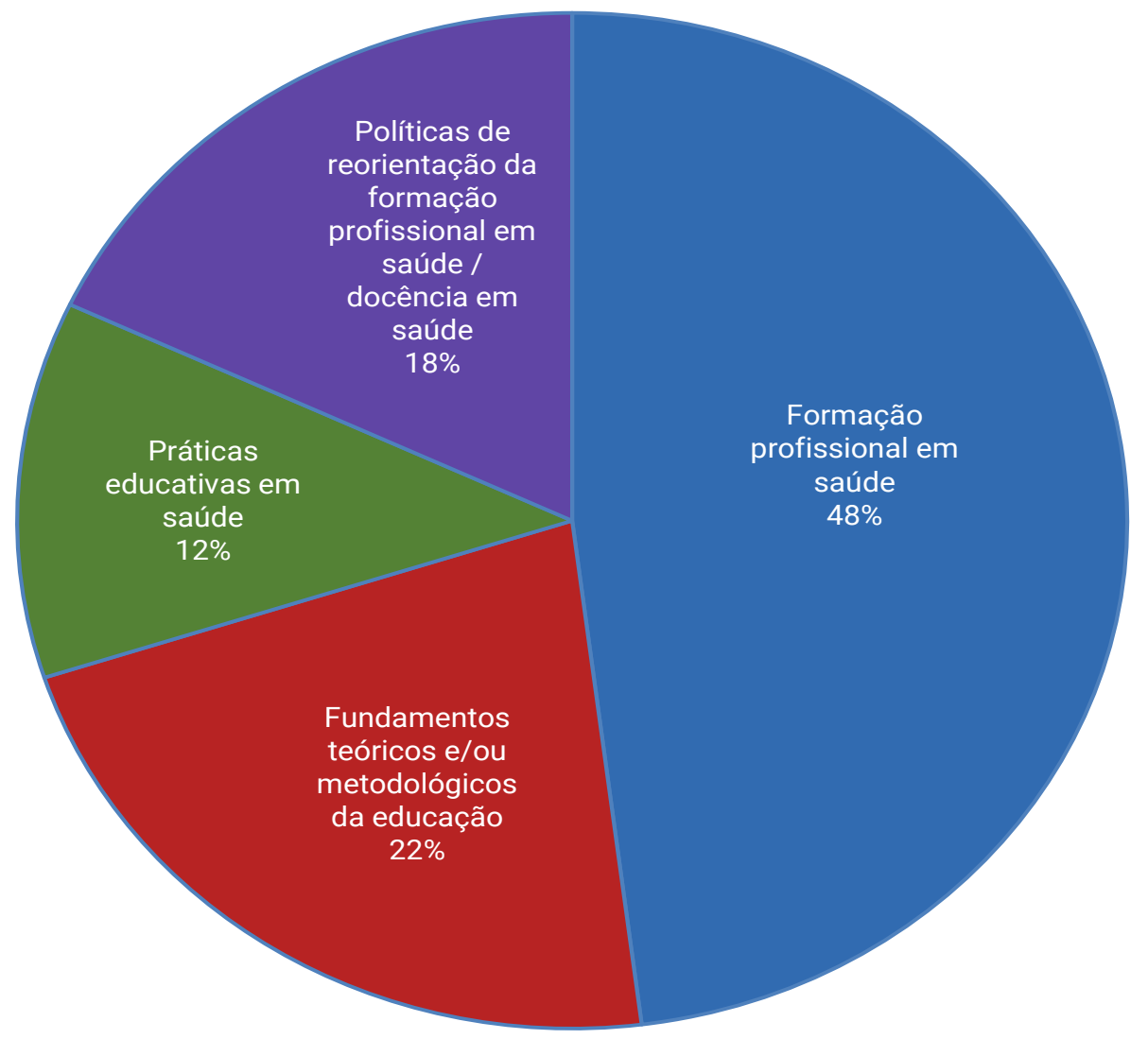

Fonte: Elaborado pelos autores

A primeira categoria, denominada "Formação profissional em saúde", abrange 216 publicações; contempla discussóes seja na educação profissional técnica de nível médio e suas diretrizes, seja na educação superior; e considera as relações entre ensino, pesquisa e extensão, envolvendo aspectos relativos ao currículo, avaliação, Diretrizes Curriculares Nacionais dos cursos de graduação em saúde, inovações pedagógicas e metodologias de ensino-aprendizagem presentes nas experiências formativas. Incluemse nesta categoria as publicaçôes voltadas para a formação de profissionais que atuam nas instituições de saúde, com o debate referente à educação permanente e educação continuada.

A importância desta categoria, que abrange o maior número de publicações, revela a vocação da revista. Inicialmente, no período de 1997 a 2000, o número restrito de 21 publicaçóes estava relacionado a esta categoria, com a predominância da temática "Pesquisa e prática pedagógica", com primazia nas discussóes relativas a metodologias de ensino-aprendizagem. Essas discussóes ampliam-se a partir de 2001, com as Diretrizes Curriculares Nacionais. A partir desse contexto, a tônica vai mudando e a temática mais expressiva que se manifestou foi "Currículo e projeto pedagógico".

Ressaltamos que as temáticas "Educação e trabalho e saúde", "Avaliação" e "Teorias e educação em saúde" também estiveram presentes, de forma significativa, no conjunto de publicaçóes desta categoria, singularmente a partir do debate a respeito da educação permanente, consonante com a avaliação da aprendizagem e as perspectivas teóricometodológicas para a formação profissional em saúde. 
Compreendemos, a partir desse movimento histórico e político, que pesquisadores e profissionais, principalmente do campo da saúde, recorreram à Interface para apresentar e problematizar as suas experiências ou socializarem seus estudos. Destarte, a revista representou um relevante veículo de socialização em um período de grande efervescência da discussão de projetos inovadores e de importantes marcas na formação em saúde, acima de tudo respaldada no que as próprias diretrizes preconizam, bem como a partir dos processos de regulação de qualidade que incidem nos cursos.

Desse modo, é relevante problematizar: que profissional da saúde estamos querendo formar? Nesse processo de transição, vivido a partir de 2001, de mudanças e desafios, intensifica-se a discussão sobre os caminhos para a formação em nível superior de diferentes profissionais do campo da saúde. É nesse sentido que emergem alternativas que procuram se pautar na perspectiva da inovação no currículo e projeto pedagógico, como: problematização; aprendizagem baseada em problemas; medicina baseada em evidências; adoção das narrativas; e metodologias ativas e participativas.

Entretanto, é conveniente advertir a necessidade de certo cuidado para não cairmos em um enquadramento em determinadas opçôes. Certamente, essas alternativas são recursos relevantes, mas não representam necessariamente uma saída para os problemas e desafios da formação profissional, o que implica na reflexão: como elas podem dialogar com essa formação, em uma perspectiva inovadora? Indubitavelmente, esse é um desafio constante a considerar. Inegáveis avanços decorrentes das experimentaçóes nos cotidianos nos cursos de saúde precisam ultrapassar visóes que podem enveredar por certo neotecnicismo e acrescentar questóes de fundo ao debate.

Outro movimento importante a se considerar é o que surge no campo das políticas interministeriais. Nesse sentido, elegemos uma segunda categoria de análise: "Políticas de reorientação da formação profissional em saúde/Docência em saúde”. Apesar de essa categoria ser constitutiva da primeira, relativa à formação profissional em saúde, optamos por elegê-la para destacar tanto o número significativo de 83 publicaçóes que ela abrange quanto o seu foco no Sistema Único de Saúde (SUS), com base em estudos que analisam as políticas públicas do Ministério da Saúde, em articulação com o Ministério da Educação, e programas locais das universidades. Essas publicações estão acompanhadas de um movimento vivido entre 2009 e 2017, com os programas indutores. Evidenciamos a existência, entre 1997 e 2003, de algumas publicaçôes associadas a esta categoria, singularmente com a discussão de estudos e experiências que dizem respeito ao Programa Uma Nova Iniciativa na Educação dos Profissionais de Saúde: União com a Comunidade (Programa UNI).

Portanto, trazer à tona esta categoria nos remete à compreensão e problematização do estreitamento entre Ministérios e das políticas de regulação na saúde e na educação. A temática fortemente presente no âmbito desta categoria é "Educação e trabalho em saúde”, com relevantes discussóes que tratam da educação continuada (especialmente na esteira do debate relacionado à Residência Multiprofissional em Saúde), educação permanente, educação interprofissional, interprofissionalidade, integração ensinoserviço e educação popular em saúde. De forma não menos importante, esteve presente também a temática da "Avaliação", principalmente de programas e políticas de saúde.

A predominância da temática "Educação e trabalho em saúde" perpassa pelo entendimento de que mudanças no campo da educação devem gerar impacto na atenção à saúde. Anteriormente, compreendemos uma série de mudanças, 
principalmente no âmbito do Ministério da Educação, com a promulgação das diretrizes curriculares, já citadas acima. A contar de 2009, o Ministério da Saúde busca articular-se de maneira mais incisiva com o Ministério da Educação, engendrando forma híbrida de regulação da qualidade sensível às políticas indutoras necessárias à transformação das redes de atenção à saúde. Assim, revela-se um compromisso com uma formação profissional que repercuta no SUS, dada sua centralidade no âmbito dessas políticas.

Desse modo, essas políticas provocam o surgimento de um grande número de publicaçóes que socializam as relevantes experiências delas derivadas e que merecem ser destacadas, considerando os desafios atuais no campo da educação em saúde. Nesse sentido, cumprem um papel importante a Política Nacional de Humanização (PNH), a Política Nacional de Educação Popular em Saúde (PNEPS-SUS), o Programa de Educação pelo Trabalho para a Saúde (PET-Saúde) e o Programa Mais Médicos. Exploramos essas políticas brevemente na próxima seção, quando tratamos dos suplementos temáticos da revista. Compreendemos, nesta categoria, a intencionalidade e o compromisso da revista, coincidente com o movimento histórico e político, em dar ênfase e visibilidade a temáticas que discutam resultados, impactos e repercussões dessas políticas nas questôes relativas à educação em saúde, considerando a demanda de publicação e de compartilhamento das experiências que emergiram a partir delas.

A terceira categoria eleita nomeia-se "Práticas educativas em saúde". Abrange 52 publicaçôes e, conquanto estejam, de certo modo, relacionadas à formação profissional, incluem as experiências ligadas aos usuários, ao ensino e às aprendizagens em serviços de saúde no diálogo com a comunidade. Embora não represente um número tão expressivo de publicaçóes, compreendemos a especificidade e a visibilidade dessas experiências, por meio de um conjunto de trabalhos que exploram uma diversidade de questôes, sendo predominantes as temáticas "Educação e trabalho e saúde" e "Pesquisa e prática pedagógica”, especialmente as que discutem metodologias de ensinoaprendizagem.

Por fim, a última categoria - "Fundamentos teóricos e/ou metodológicos da educação” - abrange 101 publicaçôes, com a discussão de aspectos teórico-conceituais; temáticas gerais do campo da educação, da pesquisa e de suas metodologias; práticas pedagógicas; e as publicações que abarcam a docência universitária.

É nessa categoria que se ressaltam as temáticas "Teorias e educação", "Formação universitária" e "Formação e trabalho docente". Por meio dela, podemos compreender que a Interface cumpre uma finalidade social importante: a de possibilitar o diálogo e de reconhecer a potência de uma formação interprofissional, na medida em que abre espaço para a publicação de um conjunto de temas não diretamente vinculados à saúde, mas que citam questôes específicas do campo da educação. Esse diálogo é favorecido porquanto a revista circula densamente entre profissionais e pesquisadores do campo da saúde. Portanto, são afetados, de certo modo, pelo conjunto de publicações específicas dessa categoria. Observa-se uma potência pedagógica e política dos temas ali tratados, repercutindo na formação dos profissionais da saúde que atuam como professores, os quais, curiosamente, mesmo sem formação específica, compartilham experiências de ensino postas em ação.

Essas experiências acabam se constituindo igualmente preciosas para a formação sempre inconclusa dos profissionais e pesquisadores do campo da educação, por 
meio da diversidade de estudos, experiências e perspectivas teórico-metodológicas que circulam e que, por mais que se situem em cursos e práticas da área da saúde, revelam interessantes possibilidades para o campo mais específico da educação. Por conseguinte, reforça-se o caráter interdisciplinar da Interface, que, ao contestar as fronteiras estanques e frágeis entre conhecimentos da educação, da saúde e de outras áreas, fortalece a relação dialógica entre pesquisadores na produção de inovaçôes curriculares e pedagógicas efetivas.

De modo geral, podemos refletir: por que essas categorias de análise são importantes? Ousamos responder que elas estão intimamente relacionadas com o movimento histórico, considerando as políticas, pesquisas e ações que emergiram ao longo dos vinte anos no campo da educação e saúde. São coincidentes com as perspectivas teórico-metodológicas que induziram mudanças e revelaram possibilidades para a formação profissional. A partir do nosso recorte de análise, logo compreendemos que a revista Interface constituiu-se como um veículo que possibilitou aprendizagens, compartilhamento de experiências e o estreitamento entre diferentes campos, destacadamente entre educação e saúde.

Para inventariar o caminho da revista, nesse resgate histórico, damos visibilidade, na próxima seção, a alguns componentes da revista que reforçam a relação entre os temas pautados e o contexto histórico e político vivido. São componentes que guardam especificidades que merecem ser destacadas, porque revelam temáticas priorizadas pela equipe editorial nesse âmbito.

\section{Ensaios, dossiês e suplementos temáticos: breve retrospectiva}

Quando identificamos os ensaios, dossiês e suplementos temáticos, percebemos que existe uma postura ativa da equipe editorial de pautar alguns temas. Em vista disso, revelam o posicionamento da Revista ao dar sustentação às relações entre as publicações e o contexto das políticas, açóes e pesquisas no campo da educação e saúde.

Os ensaios (1997 a 2001) e dossiês (2002 a 2017) descortinam a intencionalidade de trazer temas importantes e abrangentes, marcados pelo diálogo interdisciplinar e interprofissional, em coerência com a proposta da Interface. Isso posto, apontamos os 13 temas explanados nos ensaios e dossiês que contemplam publicações que possibilitam a interface com a educação.

\section{Modelos comunicacionais e práticas de saúde (1997)}

Ao situar o "[...] momento de transição e crise, em que o pensamento científico liberta-se das certezas [...]" ${ }^{4}$ (p. 5), o texto de apresentação destaca o nascimento da revista e seu compromisso com o diálogo. Estão presentes nesta seção manuscritos que se situam na categoria "Fundamentos teóricos e/ou metodológicos da educação".

\section{Produção de conhecimento, ensino-aprendizagem e educação (1998)}

A apresentação do terceiro número da revista sinaliza a intenção de: "[...] traçar, com maior precisão, a rede de relações de sentido que constrói sua identidade" (p. 7). Nesse sentido, a revista demarca sua posição “[...] em favor do humano”s (p. 7) ao situar o contexto marcado pelo avanço científico e tecnológico. É no seio dessa 
afirmação de identidade que parece propícia a discussão em torno da produção de conhecimento, ensino-aprendizagem e educação.

\section{A universidade no limiar do século XXI (1999)}

Os quatro textos presentes neste bloco temático promovem a interface com a educação, discutem questôes atinentes à universidade, sua missão, vocação e função, bem como aos processos de inovação.

\section{Violência contra mulheres: interfaces com a saúde (1999)}

Apesar de o recorte ser a violência contra mulheres, destacamos a existência de publicaçóes que se aproximam da discussão violência e educação, ancorada nos fundamentos históricos da educação e na análise de seus reflexos no cotidiano escolar.

\section{Pacientes e passageiros (2000)}

Refere-se à temática da tecnologia. "Pacientes e passageiros" é o título de um dos artigos, além de nomear a seção de ensaios. $\mathrm{O}$ artigo faz uma ponderação "[...] sobre as consequências do uso de novas tecnologias nas práticas médicas, para os pacientes em hospitais. Utiliza-se de uma analogia com os passageiros de viagens aéreas, nas salas de espera dos aeroportos”' (p. 11). Na interface com a educação, identificamos um artigo que reflete uma proposta metodológica para a prática profissional, fundamentado na análise das transformaçóes da técnica em medicina.

\section{Educação (2001)}

$\mathrm{Na}$ apresentação do tema, Pereira Junior ${ }^{7}$ (p. 7) situa o momento histórico e destaca que "a aceleração das transformações, suportada pelas inovaçôes tecnológicas, tem trazido consequências para todos os níveis de atividade humana” ". Diante desse contexto, justifica a necessidade da aprendizagem para o exercício de toda prática social para permitir " [...] um adequado posicionamento frente ao panorama de complexidade com que nos defrontamos" ". Desse modo, neste bloco temático, a revista socializa cinco ensaios que discutem aspectos diversos da área da educação.

\section{Ensino da profissão (2002)}

Ao apresentar a décima edição da revista, na qual se faz presente este bloco temático, os editores destacam o compromisso da revista “[...] com a discussão e reflexão sobre os problemas da formação da profissão e das práticas que envolvem o campo da Saúde” (p. 7), reafirmando sua identidade, na interface com a educação.

\section{Tempos de mudança (2003)}

O tema da inovação está presente no 13o número da revista. Ela convida os leitores a "[...] refletirem sobre a Educação em tempos de mudança" (p. 7), a partir de trabalhos que trazem reflexóes e experiências inovadoras. 
Das dimensões pedagógicas para a construção da cidadania no exercício do controle social (2007)

Neste dossiê, Aciole $^{10}$, em um artigo de mesmo título, discute a prática do controle social no SUS em sua dimensão pedagógica.

\section{Cuidado (2008)}

A dimensão cuidadora é o foco deste bloco temático, no qual estão presentes textos que pontuam a formação profissional nos cursos de graduação, tendo em vista $o$ cuidado no trabalho em saúde.

\section{Homeopatia no Sistema Único de Saúde (2008)}

O ensino da homeopatia é o foco de artigos deste dossiê, que fazem a interface do tema com a educação, no âmbito da categoria de formação profissional em saúde.

\section{Formação em saúde (2008)}

Este dossiê é publicado "no momento em que enfrentamos desafios e abrimos perspectivas de transformação do ensino superior em saúde, (re)construindo processos formativos significativos para alunos, professores e comunidade [...]"11 (p. 695).

\section{Dermeval Saviani: cinquenta anos de trabalho e educação (2017)}

A publicação em homenagem ao professor Dermeval Saviani surge no contexto dos vinte anos da revista, "[...] contextos atuais difíceis e de incertezas [...]"12 (p. 488). Assim, torna-se "[...] tanto um ato de justiça quanto de protesto e resistência"13 (p. 493). Resistência "[...] ao movimento gravemente regressivo da conjuntura atual que se manifesta na educação básica, assim como em outros âmbitos [...]”13 (p. 493). Nesse contexto, os artigos trazem à tona a trajetória do educador, sua produção, as discussóes relativas a trabalho e educação, pedagogia histórico-crítica e a concepção de currículo.

Além dos ensaios e dossiês, apontamos cinco suplementos temáticos que contemplam publicações que se aproximam da área da educação. São temas que estabelecem uma relação forte com a categoria de análise relativa às políticas de reorientação da formação profissional em saúde/docência e saúde:

\section{Humanização da saúde (2009)}

Considerando os esforços da PNH, na época, em seus cinco anos de existência, este suplemento “[...] se inscreve neste movimento e opção ético-política: espaço de apresentação, de afirmação, mas também de arguição, que impõe movimento de reflexão, de reposicionamentos [...]"14 (p. 491). As publicações que fazem interface com a educação consideram os princípios da $\mathrm{PNH}$.

\section{Apoio institucional na Política Nacional de Humanização (2014)}

O suplemento considera a estratégia do apoio institucional, utilizada pela PNH, dando visibilidade a "[...] práticas de apoio e seus efeitos na transformação dos 
processos de trabalho e dos sujeitos (trabalhadores e usuários), ancorada em muitas experiências desenvolvidas nos últimos anos no $\operatorname{SUS}{ }^{15}$ (p. 806). Destacamos a publicação de artigos que consideram essa estratégia na formação profissional em saúde e que pontuam metodologias e experiências de integração ensino-serviço.

\section{Educação Popular em Saúde (2014)}

Considerando a institucionalização da Política Nacional de Educação Popular em Saúde (PNEPS-SUS) e a proposta da Política Nacional de Participação Social, este suplemento apresenta reflexóes e sistematiza experiências de Educação Popular em Saúde (EPS); possibilita o reconhecimento e a legitimação desse campo; e demostra o compromisso com a democratização do SUS.

\section{Experiências exitosas de formação em Saúde nas Redes de Atenção à Saúde e a interprofissionalidade: os grupos PET-Saúde e a mudança nos cursos de graduação em saúde (2015)}

O suplemento apresenta pesquisas e relatos de experiências desenvolvidos no âmbito do Programa de Educação pelo Trabalho para a Saúde (PET-Saúde). É publicado em um contexto marcado por mudanças nos cursos de graduação em saúde, pela implantação de novas Diretrizes Curriculares e pela Lei no 12.871 , que criou o Programa Mais Médicos.

\section{Provimento médico no âmbito do SUS (2017)}

O suplemento apresenta publicações que se dedicam à “[...] análise das políticas públicas de provimento médico no Brasil, implantadas nos últimos anos para enfrentar a escassez de médicos em áreas rurais remotas e em áreas das periferias urbanas”16 (p. 1083). Debatem-se políticas como o Programa de Valorização do Profissional da Atenção Básica (Provab) e o Projeto Mais Médicos (PMM) para o Brasil. As publicações que fazem interface com a educação tratam da educação permanente de profissionais da saúde, da supervisão acadêmica de médicos, da educação continuada e do currículo da educação médica.

\section{Os significados dessa trajetória e os desafios para as próximas décadas}

Não sou forte e nem poderosa. Tampouco estou na flor dos 20 anos.

Levo no rosto uma história curtida e que me ajuda a envelhecer.

Não vivi sem resultados, minha vida não foi inóspita.

Sempre que mencionam em tom de elegia de como era nos áureos tempos, sorrio.

Recordo, agradecida, uma trajetória intensa e ruborizo-me. A beleza, a esta altura, não me lisonjeia. Opto por ser a heroína das ideias e das ações que desenvolvi, em especial por me haver submetido ao que o corpo e a imaginação me ditaram. Nélida Piñon ${ }^{17}$ (p. 11) 
Quais leituras podemos fazer a partir desse conjunto de temas que foram socializados ao longo dos vinte anos no fluxo contínuo de publicações, ensaios, dossiês e suplementos?

A revista assume e mantém sua identidade e se posta, direta ou indiretamente, enquanto periódico disposto a marcar posição no campo das políticas de saúde, referenciadas no SUS e que precisam se sustentar em decisôes e ações institucionais que favoreçam a implementação das inovaçôes no campo da formação em saúde com claros e indissociáveis vínculos com os serviços de saúde.

Nota-se a acuidade da equipe editorial frente a temas emergentes ligados ao campo da educação, saúde e comunicação. Nesse quesito, observa-se a perspectiva proativa indutora e introdutora de novas nuances que transitam nessas áreas, que demandam reflexôes e trazem ao debate diferentes e plurais abordagens tanto teóricas quanto metodológicas.

A revista parece não assumir como única prerrogativa de sua existência o compromisso com a socialização do conhecimento produzido em pesquisas e experiências educativas inovadoras. Mas é importante destacarmos essa intencionalidade política na celebração desses vinte anos e recuperarmos esse papel vultoso que a revista vem cumprindo de dar vazão às várias experiências de formação profissional e práticas educativas em saúde, das discussões no âmbito dos fundamentos da educação e das políticas de reorientação da formação profissional. A revista fez um diálogo com os movimentos que se constituíram dentro da formação de profissionais, sendo influenciada e provocada por projetos de indução dos Ministérios da Saúde e da Educação. Nessa perspectiva, ajuda a construir uma memória de resistência, de inovação e de luta.

Compreender as grandes tendências transversalizadas nas temáticas e respectivas categorias de análise é compreender os seus significados, inclusive do ponto de vista político, que se constroem com a possibilidade de induzir reflexóes e práticas diferentes, permitindo que os autores se debrucem sobre isso ao trazerem suas experiências que abrem espaço às contradiçóes.

A revista oportuniza a participação de pesquisadores de áreas afins de modo que contribuam com os saberes para o melhor entendimento da tríade educaçãocomunicação-saúde, exercitando em ato os princípios da educação, trabalho e pesquisa interprofissionais, pilares que vêm se firmando como fecundos desafios da formação profissional no século XXI.

Observa-se que a pressão pela internacionalização e a ampliação nas bases de indexação colaboraram para a intensificação dos diálogos entre autores nacionais e estrangeiros, o que pode ocasionar desdobramentos positivos no campo da produção acadêmica em saúde.

Ao mapear a trajetória da revista na categoria Educação nos deparamos com a complexidade de organizar o material empírico existente. No movimento de ora garimpar temáticas, ora definir categorias de análise, constatamos a linha tênue que separa tais práticas, pois veio à tona a forte imbricação entre elas.

Interrogamo-nos acerca da fidelidade da asserção por nós produzida de que a Revista Interface é (se tornou) uma instância privilegiada de contrarregulação no campo da formação em saúde. Entendendo contrarregulação como uma reação propositiva que transcende a crítica a um estado de coisas, que cria cenários 
favorecedores à contestação e que denuncia/anuncia novas possibilidades, cremos que a asserção faz sentido e produz novos sentidos a cada número que circula. Ponto de encontro, ponto de apoio, ponto de desestabilização? De tudo um pouco.

Observa-se a proatividade do periódico no sentido de indução à reflexão e convite ao debate sobre temáticas emergentes, consoante às políticas de reorientação do eixo de formação profissional em saúde ou sensível aos movimentos que lutam pelo direito à diversidade, reconhecimento das questóes de gênero, entre outros temas polêmicos.

Considerando as políticas atuais que afetam tão forte e de modo nefasto a agenda da educação e da saúde, enfatizamos a importância que a Revista mantenha sua autonomia na linha editorial que produz, a qual se referencia no ideário da qualidade social. Ademais, desejamos que saiba reinventar-se a cada novo desafio, de modo a cumprir com responsabilidade seu compromisso como instância de divulgação e socialização do conhecimento novo, produzido em nome de uma ciência eticamente implicada.

\section{Contribuições dos autores}

Todos os autores participaram ativamente de todas as etapas de elaboração do manuscrito.

\section{Agradecimentos}

À professora Vera Lucia Garcia, colaboradora de Interface, responsável pelo levantamento e categorização dos trabalhos do Eixo Educação publicados na revista no período de 197-20017 e posterior organização do banco de dados, a partir dos quais este artigo foi elaborado.

\section{Direitos autorais}

Este artigo está licenciado sob a Licença Internacional Creative Commons 4.0, tipo BY (https://creativecommons.org/licenses/by/4.0/deed.pt_BR).

$((\mathrm{cc}) \mathrm{Br}$

\section{Referências}

1. Minayo MCS, organizadora. Pesquisa social: teoria, método e criatividade. 29a ed. Petrópolis: Vozes; 2010. p. 9-29.

2. Bardin JL. Análise de conteúdo. Lisboa: Ediçốes 70; 1977.

3. Saviani D. Pedagogia histórico-crítica: primeiras aproximações. 11a ed. Campinas: Autores Associados; 2012.

4. Calvino I. Apresentação. Interface (Botucatu). 1997; 1(1):5. doi: http://dx.doi. org/10.1590/S1414-32831997000200001.

5. Apresentação. Interface (Botucatu). 1998; 2(3):7. doi: http://dx.doi.org/10.1590/ S1414-32831998000200001. 
6. Sant'Anna DB. Pacientes e passageiros. Interface (Botucatu). 2000; 4(6):11-20. doi: http://dx.doi.org/10.1590/S1414-32832000000100002.

7. Pereira Júnior A. Apresentação. Interface (Botucatu). 2001; 5(9):7-8. doi: http:// dx.doi.org/10.1590/S1414-32832001000200001.

8. Apresentação. Interface (Botucatu). 2002; 6(10):7. doi: http://dx.doi.org/10.1590/ S1414-32832002000100001.

9. Cyrino EG. Apresentação. Interface (Botucatu). 2003; 7(13):7-8. doi: http://dx.doi. org/10.1590/S1414-32832003000200001.

10. Aciole GG. Das dimensões pedagógicas para a construção da cidadania no exercício do controle social. Interface (Botucatu). 2007; 11(23):409-26. doi: http://dx.doi. org/10.1590/S1414-32832007000300002.

11. Batista NA, Batista SH. Formação em saúde: investigando práticas no âmbito de cursos de graduação. Interface (Botucatu). 2008; 12(27):695. doi: http://dx.doi. org/10.1590/S1414-32832008000400001.

12. Scheffer M, Schraiber LB. Interface, vinte anos: a Saúde Coletiva em tempos difíceis. Interface (Botucatu). 2017; 21(62):487-91. doi: http://dx.doi.org/10.1590/180757622017.0288 .

13. Ramos MN. Apresentação. Interface (Botucatu). 2017; 21(62):493-6. doi: http:// dx.doi.org/10.1590/1807-57622017.0156.

14. Pasche DF, Passos E, Barros MEB. A humanização do SUS como uma política do comum. Interface (Botucatu). 2009; 13 Suppl 1:491. doi: http://dx.doi.org/10.1590/ S1414-32832009000500001.

15. Pereira EHP, Oliveira GN, Barros MEB, Rodrigues TR, Souza TP. Apresentação. Interface (Botucatu). 2014; 18 Suppl 1:805-6. doi: http://dx.doi.org/10.1590/180757622014.1153 .

16. Padilla M. Editorial. Interface (Botucatu). 2017; 21 Suppl 1:1083-6. doi: http://dx.doi. org/10.1590/1807-57622017.0749.

17. Piñon N. Livro das horas. Rio de Janeiro: Editora Record; 2012.

The text provides an overview of the twenty years of the Education axis in the journal Interface and analyzes this trajectory based on its publications. The examination of the articles reveals the predominant trends and enables us to reflect on the challenges to the next decades. The categories of analysis: Professional Health Education, Reorientation Policies for Professional Health Education/Health Teaching, Educational Health Practices and Theoretical and/or Methodological Foundations of Education are employed to encompass the set of themes approached by the authors in the historical period of the study, in the journal's different spaces, in a close relationship to the journal's purposes in the sphere of socialization of knowledge in the field of education and health. The conclusion is that Interface has been an important space for the systematization of the general challenges of education and of the specific challenges of health education, as well as for careful reflection on them, potentializing qualitative advances in professional education.

Keywords: Education and health. Professional education. Socialization of knowledge. Twenty years of Interface. 
El texto rescata los veinte años del eje Educación en la revista Interface y problematiza esa trayectoria a partir de sus publicaciones. La mirada hacia esos trabajos revela las tendencias predominantes y reflexiona sobre los desafíos para las próximas décadas. Las categorías de análisis: Formación Profesional en Salud; Políticas de Reorientación de la Formación Profesional en Salud/ Docencia en Salud; Prácticas Educativas en Salud y Fundamentos Teóricos y/o Metodológicos de la Educación se ponen en acción para contemplar el conjunto de temas abordados por los autores en el período histórico del estudio, en los diferentes espacios de la revista, en estrecha relación con sus finalidades en el ámbito de la socialización del conocimiento en el campo de la educación y de la salud. Se concluye que la revista ha mostrado ser un espacio importante de sistematización y reflexiones, tanto de los desafíos generales de la educación como de los específicos de la educación en salud, potenciando avances cualitativos en la formación profesional.

Palabras clave: Educación y salud. Formación profesional. Socialización del conocimiento. Veinte años de Interface. 